\title{
Effect of Ozonated Olive Oil in Topical Application towards Osteoblast Number and Angiogenesis of Alveolar Bone in Periodontitis Healing Process (in vivo study in Sprague dawley Rats)
}

\author{
Dahlia Herawati*, Deassy Anggraeni, Ariska Ratih Damayanti \\ Department of Periodontics, Faculty of Dentistry, Universitas Gadjah Mada, Yogyakarta, Indonesia
}

\begin{abstract}
Ozonated olive oil has been widely used as a local infection therapy to overcome bacterial resistance from antibiotics with systemic administration. However, the disadvantage of systemic antibiotics is it cannot be used in large doses for local infection therapy. Periodontitis is an infectious disease that causes alveolar bone damage. In the periodontitis healing process, osteoblasts and angiogenesis play essential roles in bone regeneration. The study aims to determine the effect of topical application ozonated olive oil to osteoblasts number and angiogenesis of alveolar bone in periodontitis healing process using in vivo study. 32 Sprague Dawley rats were divided into two groups: the treatment and placebo groups, 16 rats in each group. The induction of periodontitis was performed by ligating lower incisor with silk ligature for seven days. The treatment group received ozonated olive oil, and the placebo group received $1 \%$ of CMC-Na twice a day. Four rats from each group were necropsied on day 3, 5, 7, and 14 and then processed into histological sample preparations by hematoxylin-eosin staining and counted the number of osteoblast and blood vessels. All collected data were analyzed using two-way ANOVA and posthoc LSD test. The average number of osteoblasts, blood vessels in the treatment group were significantly higher than the placebo group $(\mathrm{p}<0.05)$ either on day 3, 5, 7, and 14. Results showed the ozonated olive oil increase the regeneration of alveolar bone in the periodontitis healing process in Sprague Dawley. Therefore ozonated olive oil has the effect of periodontal tissue regeneration.
\end{abstract}

Keywords: Periodontitis; Alveolar bone damage; Ozonated olive oil; Osteoblast; Angiogenesis

\section{INTRODUCTION}

In the era of antibiotic resistance, we need a naturally occurring substance like Ozone to treat infection without any toxic side effects (Srinivasan and Chitra, 2015). Nowadays, ozonated olive oil is widely used as local infection therapy to overcome bacterial resistance from antibiotics by systemic administration. However, the disadvantage of systemic antibiotics is that it cannot be used at a large dose for local infection therapy.

Periodontitis is a chronic infectious disease that slowly damages supporting tissues of the teeth due to the inflammation process on tissues. If the inflammation is not treated, the damage will affect alveolar bone, resulting in bone resorption (Laine et al., 2012). The goal of periodontal treatment is to eliminate inflammatory stimulus that causes bone resorption. The presence of bone formation in the inflammatory response and periodontal disease affect the outcome of treatment (Carranza et al., 2006). Onecrucial indicator of bone formation is the number of osteoblast cells in bone

*Corresponding author : Dahlia Herawati

Email : heradahlia@ugm.ac.id
(Junquiera and Carneiro, 2004). Osteoblasts are formed from osteoprogenitor cells, while osteoprogenitor cell differentiation is controlled by several growth factors, including BMPs, FGF, PDGF, and TGF- $\beta$ (Agata et al., 2007).

In the bone healing process, angiogenesis serves as an essential process in improving blood supply that will trigger the regeneration of bone tissue (Kotze et al., 2014). Growth factor that plays a role in the angiogenesis process includes Fibroblast Growth Factor (FGF), Vascular Endothelial Growth Factor (VEGF), and PlateletDerived Growth Factor (PDGF). The function of those growth factors is to stimulate endothelial proliferation, migration, and blood vessel formation (Li et al., 2003; Bauer et al., 2005).

Ozone therapy presents a great advantage when used as a support for conventional treatments, for example, to dental caries, periodontal procedures, and endodontic treatment (Nogales et al., 2008). Ozone is an unstable gas that quickly releases new oxygen molecules to form another oxygen so that ozone is used for therapy for a long time (Baysan and Beighton, 2007). The therapeutic effect of ozone showed that topical application of ozone might induce expression of growth factors such as PDGF, 
TGF- $\beta$, and VEGF in cutaneous wound healing (Kim et al., 2009). The combination of IGF-I, TGF- $\beta$, and PDGF increase the rate of bone formation and bone repair (Nancy, 2003). Ozone is profitably and practically employed as ozonated olive oil which contains the 03 molecule stabilized as an ozonide between the double bonds of a monosaturated fatty acid as oleic acid, which is ideal for topical use of 03 to treat chronically infected cutaneous and mucosal areas of the body (Kim et al., 2009).

Ozone usually is present as a gas made of three atoms of oxygen with cyclic structure (Ozdemir et al., 2013). Ozone exhibits some pharmacological actions, such as antimicrobial effect (bactericidal, viricidal, and fungicidal), antiinflammation, immunomodulator, biosynthesis (activate the metabolism of carbohydrate, protein, lipid), bioenergetics, antihypoxic, analgesic and hemostatic (Ahmed et al., 2013). The use of ozone in dentistry is available in three forms: ozonated water, ozone gas, and ozonated olive oil (Bocci et al., 2009). Ozonated olive oil is widely used as a therapeutic agent for clinical wound healing agent. Ozone in the form of ozonated olive oil is more stable and durable than the others. Ozonated olive oil also contains molecules ozonide that can trigger tissue regeneration (Mosallam et al., 2011).

The research on therapeutic effects of ozone showed that topical application of ozone increases collagen synthesis and fibroblast proliferation at the skin wound and enhances the expression of growth factors PDGF, TGF- $\beta$, and VEGF (Kim et al., 2009). Ozone chemically reacts with double bonds of carbon that exist in oleic acid, a form of unsaturated fatty acid, to form a large molecular complex called ozonide. Ozonide is useful as an antimicrobial agent by stimulating reparative and regenerative pathways at cellular level (Mosallam et al., 2011).

This research used the experimental model with Sprague dawley rats because it has similarities with human periodontal tissue. Histologically, the structure and composition of the mucosal tissue of rats showed not much difference from human mucosal tissue (Meitha and Windurini, 2003). The purpose of this research is to determine the effect of topical application of ozonated olive oil based on the number of osteoblasts and the angiogenesis of alveolar bone in the periodontitis healing process using Sprague dawley rats.

\section{METHODOLOGY}

The study was approved by Committee for Research Ethics and Integrity of the Dentistry Faculty of Universitas Gadjah Mada (Registration number: 00463/KKEP/FKG-UGM/EC/2015 and
00461/KKEP/FKG-UGM/EC/2015). This study used ozonated olive oil for the treatment group and $1 \%$ of CMC-Na application for the placebo group. The research used 32 Sprague dawley that divided into two groups consisted of 16 rats each.

The induction of periodontitis proceeds by intramuscular injection of ketamine hydrochloride $\left(0.2 \mathrm{~mL} \cdot 200 \mathrm{~g}^{-1}\right.$ body weight) for sedation effect. Subgingival mandibular incisors Sprague dawley were ligated using silk ligature for seven days. The clinical signs after induction of periodontitis were: inflammation in the gingiva, abscess, and both incisors of Sprague dawley became mobile. The treatment group then received ozonated olive oil, and the placebo group received $1 \%$ of CMC-Na. The application performed twice a day using an excavator to the periodontitis area, after curretage. On day $3,5,7$, and 14 , four rats from each group were necropsied by cervical dislocation then processed into histological sample preparations by hematoxylin-eosin staining. The active osteoblast cells shape marked by cuboidal to columnar with a basophilic nucleus and had a rough endoplasmic reticulum. The blood vessels appeared as round or oval-shaped cavity, surrounded by endothelial cells in the flat form with the dark purple nucleus, sometimes encountered red blood cells in the cavity. The number of osteoblast and blood vessels were observed by two observers using a light microscope at $400 \mathrm{x}$ magnification in 5 visual fields. Data were analysed using two way ANOVA test and Post Hoc Least Significant Difference (LSD) test.

\section{RESULT AND DISCUSSION}

The mean and deviation of osteoblast number in treatment and placebo groups increased from day $3,5,7$, and 14 . The mean of osteoblast number in the treatment group was higher than the placebo group. The result of two-way ANOVA test on observation time and application material groups obtained $p=0,000$ and $p=0,001(p<0,05)$, there was a significant difference in the number of osteoblasts based on observation time and application material although the interaction between observation time and application material did not affect the amount of osteoblast significantly $(\mathrm{p}>0,05)$.

The next comparison test was Post Hoc LSD test to determine the difference of osteoblast number between treatment and placebo group in each day group. The result of Post Hoc LSD test showed p-value $>0,05$ on day 3 , and p-value $<0,05$ on day 5,7 , and 14 . Osteoblast number on the day 5 , 7 , and 14 had significantly different between treatment and placebo group, meanwhile, on the day 3 was not significantly different. The result of Post Hoc LSD test demonstrated that there was a 


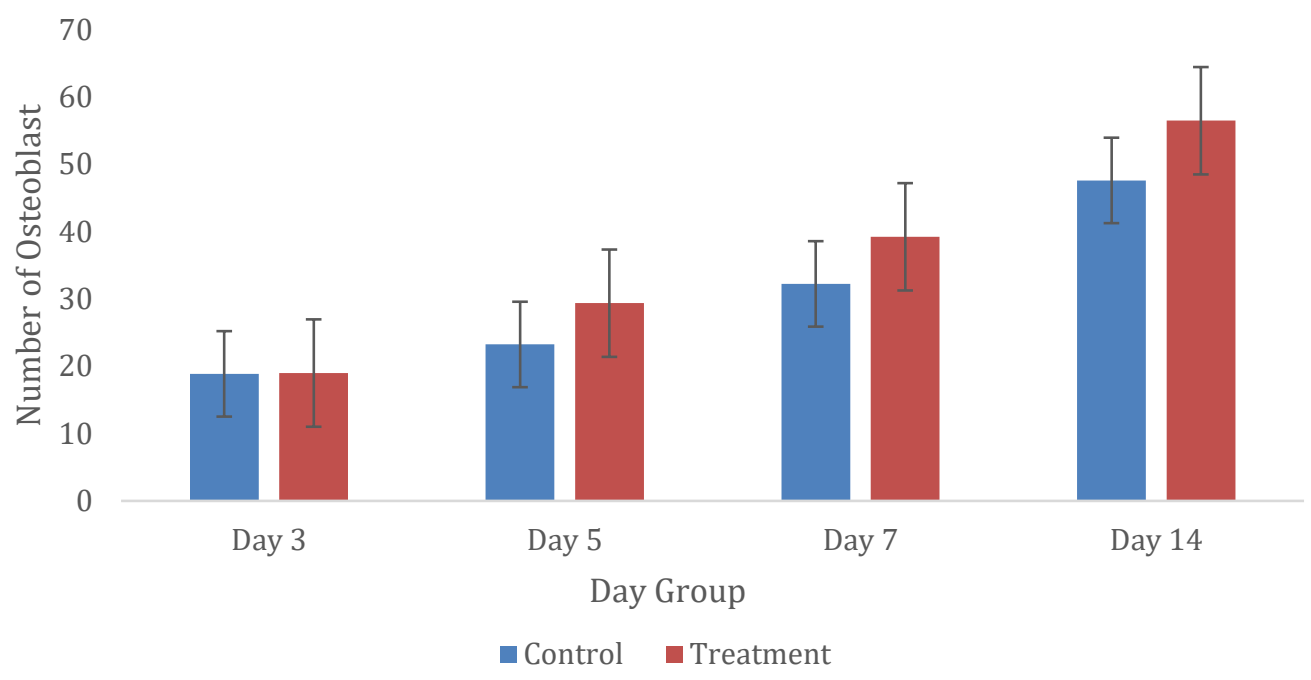

Figure 1. Comparison of osteoblast number of alveolar bone by the hematoxylin-eosin staining on days 3 , 5,7 and 14. Osteoblast number between treatment (T) and placebo group (P) significantly increase in time dependent manner $(\mathrm{p}<0.05 ; \mathrm{n}=4)$

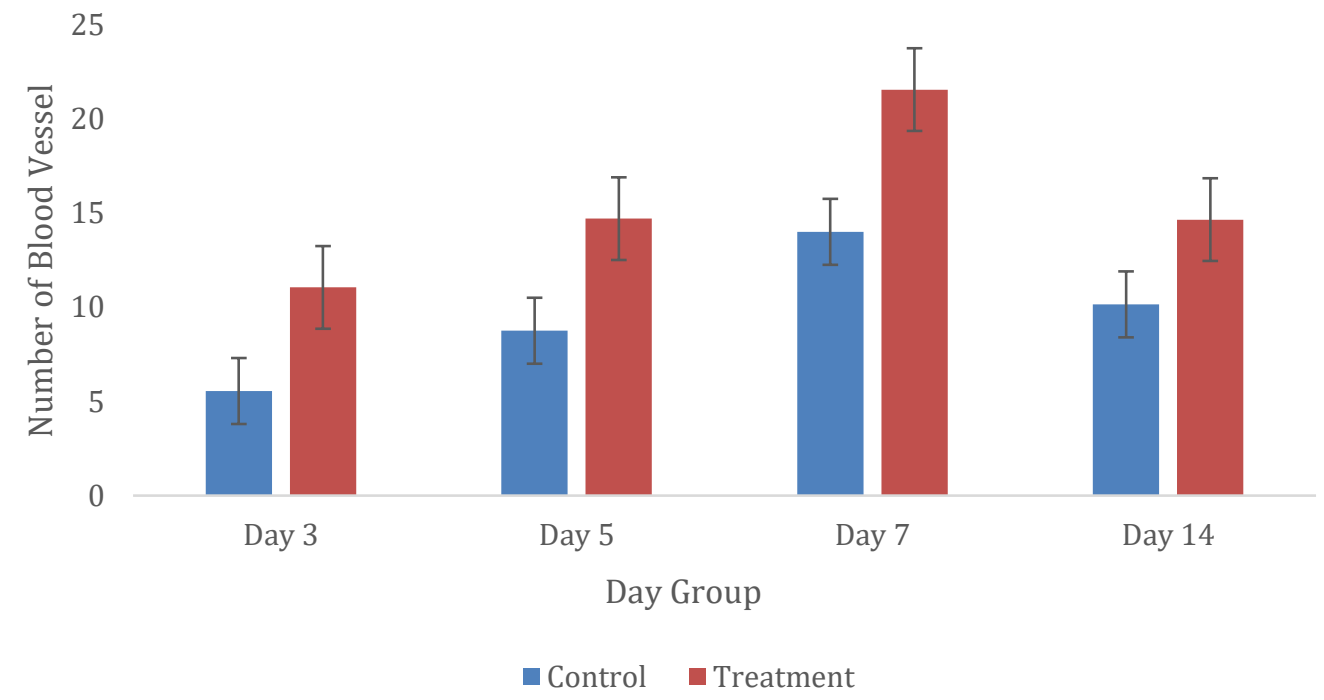

Figure 2. Comparison of blood vessel number of alveolar bone by the hematoxylin-eosin staining on days $3,5,7$ and 14. Blood number significantly increase with time but on day 14, the number of blood vessels decreased. There was a significant difference between each days group in treatment $(\mathrm{T})$ and placebo $(\mathrm{P})$ group $(\mathrm{p}<0,05 ; \mathrm{n}=4)$

significant difference between each day group in treatment and placebo group ( $\mathrm{p}<0,05)$.

The blood vessels began to form on day 3 and continued to grow. The highest number of blood vessels was found on day 7 both in the treatment and the placebo group. On day 14, the number of blood vessels decreased in both groups, with a more significant decline was found in the treatment group.

Two-way ANOVA test used to determine differences in the number of blood vessels in each group. The results of two-way ANOVA test on observation time and application demonstrated that the gap between observation time and application material affect blood vessels number were significant. Meanwhile, the interaction 


\section{Dahlia Herawati}
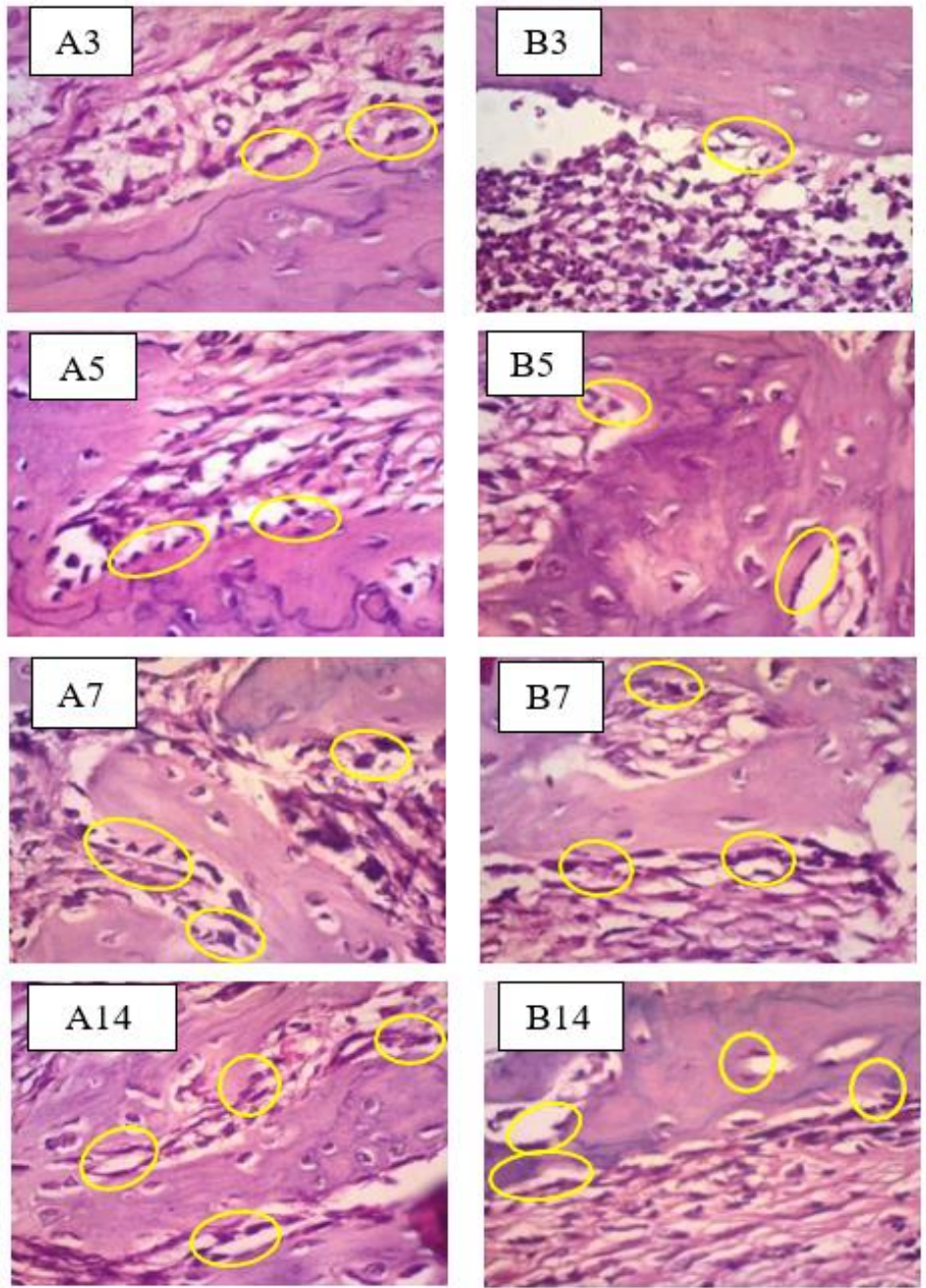

Figure 3. Hematoxylin-eosin staining of the alveolar bone on days 3, 5, 7, and 14. The ozonated olive oil treatment group A (Treatment) demonstrated the increased number of osteoblast at the alveolar bone in comparison to the placebo group B (Placebo) based on observation under microscope using magnification $\times 400$

between observation time and the use did not statistically affect the amount of blood vessels $(\mathrm{p}>0.05)$.

The result of Post Hoc LSD test also showed most of the p-value $<0.05$, but there was no The results of the study demonstrated that osteoblasts number increased from day 3, 5, 7, and continued up to day 14 both in ozonated olive oil treatment and placebo group, which indicated by the observation time that affected the number of osteoblasts significantly. Osteoblasts number was not significantly different in treatment and placebo group on day 3 . The osteoblast cell then began to be active on day 3 in bone remodeling process (Sintessa et al., 2013). The healing process was also still in the early stages of inflammation that was dominated by inflammatory cells significant difference between day 5 and 14. The result of Post Hoc LSD test on application material showed that there was a substantial difference in the amount of blood vessels between the treatment and the placebo group either on day 3, 5, 7, and 14 . (Kalfas, 2001).

On day 5 of observation, the number of osteoblasts already started to rise, and biglycan started to arise. Biglycan is one of protein that plays a vital role in bone mineralization (Roberts et al., 2008). On day 7 , the number of osteoblasts was higher than on day 3 and day 5 due to the initiation of new bone formation to synthesize and secrete matrix (Hardhani et al., 2013). Day 14 was the peak of the osteoblasts activity after bone loss (Sintessa et al., 2013). The peak of osteoblast cell activity would lead to increased collagen and matrix 

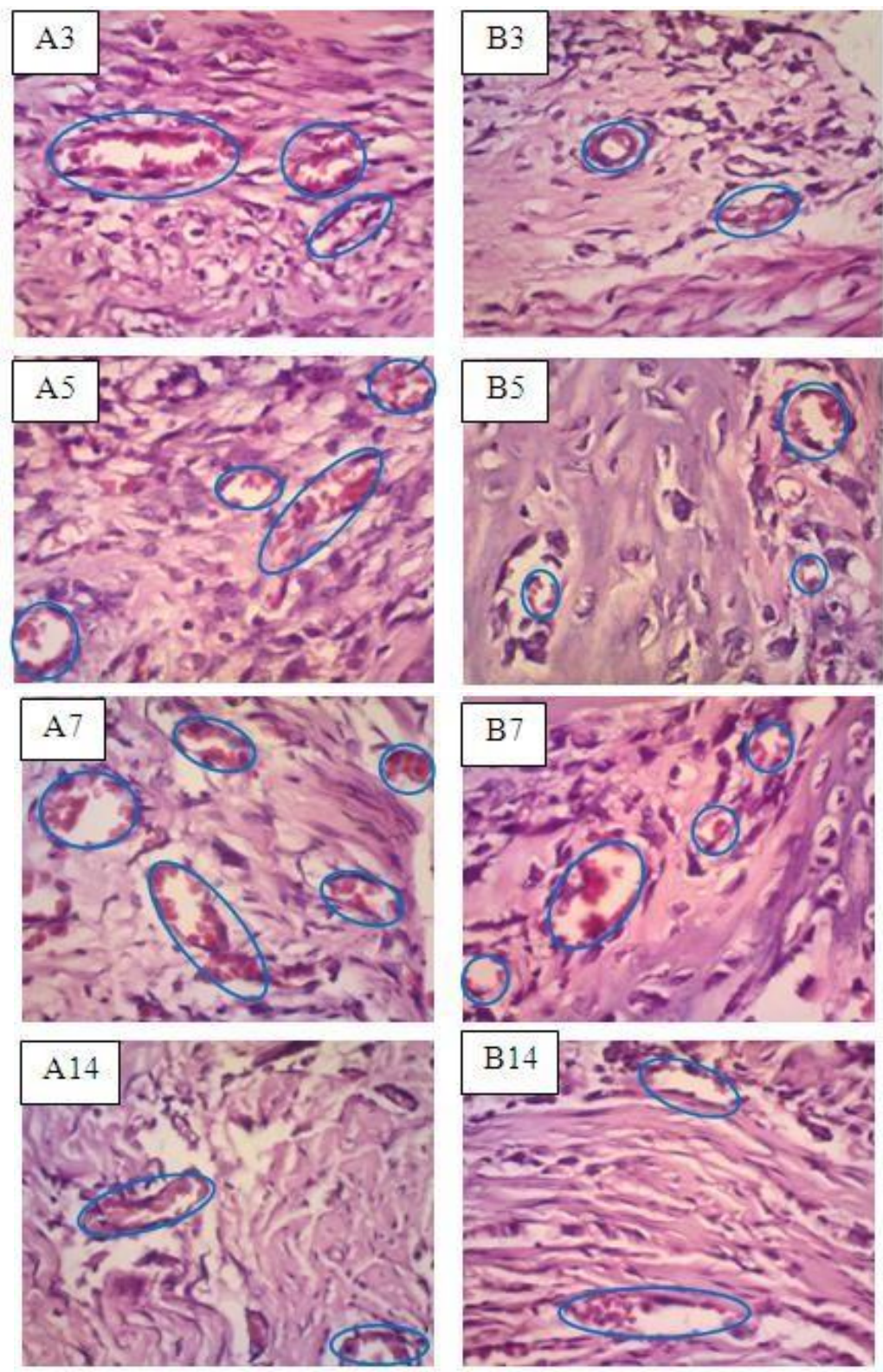

Figure 4. Hematoxylin-eosin staining of the alveolar bone on days 3, 5, 7, and 14. The ozonated olive oil treatment group (A) revealed the increased of blood vessel number at the alveolar bone until day 7 but decrease in day 14 , in comparison to the placebo group (B) based on observation under microscope using magnification $\times 400$.

deposition by osteoblasts (Junquiera and Carneiro, 2004).

The mean of osteoblasts number was significantly higher in ozonated olive oil treatment group compared to $1 \%$ of CMC-Na placebo group. This is because ozone increased the expression of growth factors such as PDGF and TGF- $\beta$. The TGF$\beta$ can enhance the activity of alkaline phosphatase, chemotaxis of osteoblasts, and osteopontin levels, thus increasing the number of osteoblasts in osteoblastogenesis (Junquiera and Carneiro, 2004). Besides, ozone also able to cause antihypoxic effect by increasing inflamed tissue metabolism, tissue oxygenation, and decreasing the inflammation by inflammatory mediator such as PGE-2. The low number of PGE-2 may affect the osteoblast production because PGE-2 function is to stimulate the expression of RANKL by osteoblast precursor and osteoblast mature will be decreased and increase the production of osteoprotegerin 
(OPG). Osteoprotegerin binding to RANKL is essential for the formation of osteoblasts (Hardhani et al., 2013; Gupta and Bansal, 2012).

Ozone also has an immunostimulating effect that activates the immune system to produce more white blood cells and cytokines such as BMP that play a role in increasing the activity of mesenchymal cells in the process of cell differentiation of osteoblasts in the area of bone damage and induce bone formation (Indahyani, 2013). In the placebo group, CMC-Na only serves as a gelling agent and emulsifier, which only reinforces the gel matrix (Nursal et al., 2010), so the $1 \%$ of CMC-Na did not affect periodontitis.

The research showed the average number of vessels increased on day 3,5 , and 7 , whereas it decreased on day 14 . The number of blood vessels peaked on day 7 both in the treatment and the placebo group. This happened because the capillaries will be formed about 3-5 days after trauma or injury (Li et al., 2003). The peak activity of blood vessels formation was on day 7 due to the expression of Vascular Endothelial Growth Factor (VEGF) reached its highest level in line with the clinical appearance of granulation tissue (Li et al., 2003; Gruendermann and Fernsebner, 2005). VEGF will stimulate angiogenesis by inducing proliferative cells and hyperpermeability blood vessels, and increase the survival function of blood vessels (Li et al., 2003).

On day 14 , the number of blood vessels in the treatment group and the placebo group were less than day 7. This happened because, in the second week, the vascularization in injured tissue was decreased (Kumar et al., 2007). The decrease is due to the mediator of angiogenesis, namely VEGF, began to decline in number after 11 days (Uchida et al., 2003). In the final stage of healing, the angiogenesis process was pressed, the number of growth factors decreased, and the inflammatory process subsided (Kotze et al., 2014). The blood vessels will start to decrease when nutritional needs in tissues were fulfilled (Kumar et al., 2007).

The decline in the average number of blood vessels that occurs on day 14 in the treatment group was more significant than the placebo group, which decreased 17.25 in the treatment group and 9.63 in the placebo group. This indicated that the CMC-Na placebo group still require an active agent for the alveolar bone healing process. CMC-Na widely used only as a base in the manufacture of the gel and it is neutral compound (Rowe et al., 2006). It showed that the CMC-Na did not have the effect of supporting the healing process.

In the time observations group, the statistic results showed that there are significant differences in the number of blood vessels between the time of observation, on day 3,5, 7, and 14. This showed that at any time of observation from day 3 to day 7 the number of blood vessels had continued to rise significantly, then decreased a significant amount also on day 14. Differences in the number of blood vessels are not substantial on day 5 and day 14 . This was due on day 14 , the number of blood vessels decreased close to the number of blood vessels on day 5. In statistic result of the application group, there are significant differences in the number of blood vessels between the treatment and placebo group. The results of this research showed that ozonated olive oil could speed up the improvement of blood vessels (angiogenesis) in the alveolar bone of the periodontitis healing process in Sprague Dawley because ozone can trigger an increase in growth factors such as VEGF, PDGF, and TGF- $\beta$, which help the formation of blood vessel structure and accelerate revascularization (Kim et al., 2009).

Ozone chemically reacts with the double bond carbons in oleic acid (a form of unsaturated fatty acid contained in olive oil) to form ozonide molecules, which effective as an antimicrobial agent and stimulates reparative and regenerative pathways at cellular level (Mosallam et al., 2011). Ozonide molecules can form aldehydes, peroxide that would damage the nucleic acids of microorganisms and degrade it into protein subunits (Geweely, 2006). Ozone also increases the synthesis of interleukins, leukotrienes, and prostaglandins that help to reduce inflammation and accelerate wound healing, and can increase the metabolism in inflamed tissue by improving the tissue oxygenation (Gupta and Bansal, 2012). Oxygen is carried by the blood vessels so that with increasing oxygenation in the injured tissue area, the number of blood vessels will also increase. Oxygenation improved by the application of ozonated olive oil will neutralize the damaging anoxic phase of bone tissue trauma so that tissue healing will go smoothly (Kotze et al., 2014).

Ozonated olive oil by topical application has a potential benefit in dentistry. This research showed one of its effect in periodontal therapy, ozone increase regeneration in periodontitis healing process. Ozone therapy has opened a new vista in treatment modalities for dental patients of all ages and applicable to a wide range of conditions of intra oral hard and soft tissues. It is especially suitable for younger patients who are often scared of "drilling" and find conventional treatment unacceptable. For older people having medical problems, that may complicate the conventional treatment, ozone therapy is easier and more efficient. Treating patients with ozone cuts off 
treatment time, eliminates bacterial count more precisely and moreover, it was completely painless, therefore increased the acceptability and compliance of the patient. Further research in ozone would bring a revolution in dental practice in near future (Srinivasan and Chitra, 2015).

\section{CONCLUSSION}

Ozonated olive oil by topical application increases the number of alveolar bone osteoblasts, blood vessels in the healing process of periodontitis on Sprague dawley. Therefore, ozonated olive oil has potential to be developed for periodontal tissue regeneration.

\section{REFERENCES}

Agata, H., Asahina, I., Yamazaki, Y., Uchida, M., Shinohara, Y., Honda, M., Kagami, H., and Ueda, M. 2007. Effective Bone Engineering with Peroisteum-derived Cells. J Dental research. 86(1):79-83.

Ahmed, J., Binnal, A., Rajan, B., Denny, C., and Shenoy, N., 2013, Ozone Applications in Dentistry: An Overview, J Exp Integr Med., 3(3):171-176.

Bauer, S.M., Bauer, R.J., and Velazquez, O.C., 2005, Angiogenesis, Vasculogenesis, and Induction of Healing in Chronic Wounds, Vase Endovasc Surg, 39(4):293-306.

Baysan, A. and Beighton, D. 2007. Assessment of The Ozone-mediated Killing of Bacteria in Infected Dentine Associated with Noncavitated Occlusal Carious Lesions. Caries Res. 41: 337-341.

Bocci, V., Borrelli, E., Travagli, V., and Zanardi, I., 2009, The Ozone Paradox: Ozone is a Strong Oxidant as Well as a Medical Drug, Medicina Research Reviews, 29(4):646-82.

Carranza, F.A., Newman F.G., and Takei, H.H. 2006. Carranza's Clinical Periodontology. Edisi 10. Philadelphia: WB Saunders. 452-458.

Geweely, N.S.L., 2006, Antifungal Activity of Ozonated Olive Oil (Oleozone), International Journal of Agriculure \& Biology, vol.8: 670675.

Gruendermann, B.J., dan Fernsebner, B., 2005, Buku Ajar Keperawatan Perioperatif, EGC, Jakarta: 519

Gupta, G and Bansal, M. 2012. Ozone therapy in periodontics. Journal of Medicine and Life. 5 (1): 59-67.

Hardhani, P.R., Lastianny, S.P., dan Herawati, D. 2013. Pengaruh Penambahan Platelet-Rich Plasma Pada Cangkok Tulang terhadap Kadar Osteocalcin Cairan Sulkus Gingiva pada Terapi Poket Infraboni. Jurnal PDGI. 62(3): 75-82.
Indahyani, D.E. 2013. Minyak Ikan Lemuru (Sardinella longicep) Menurunkan Apoptosis Osteoblas Pada Tulang Alveolaris Tikus Wistar. Dent.J. 46(4). 185-189.

Junquiera, L.C and Carneiro, J. 2004. Histologi Dasar: Teks \& Atlas (terj). Edisi 10. Jakarta: EGC. 134-156.

Kalfas, I.H. 2001. Principles of Bone Healing. Neurosurg Focus. 10(04):1-4.

Kim, H.S, Noh, S.U., Han, Y.W., Kim, K.M., Kang, H., Kim, H.O., dan Park, Y.M. 2009. Therapeutic Effects of Topical Application of Ozone on Acute Cutaneous Wound Healing. J Korean Med Sci. 24(3): 68-74.

Kotze, M., Butow, K.W., Olorunju, S.A., and Kotze, H.F., 2014, Ozone Treatment of Alveolar Bone in the Cape Chacma Baboon Does Not Enhance Healing Following Trauma, J. Maxillofac. Oral Surg., 13(2): 140-147.

Kumar, V., Ramzi S.C., dan Stanley, L.R., 2007, Buku Ajar Patologi, EGC, Jakarta:76

Laine, M.L., Crielaard, W., and Loos, B.G. 2012. Genetic Susceptibility to Periodontitis. Periodontology 2000. 58:37-68.

Li, W.W., Tsakayannis, D., and Li, V.W., 2003, Angiogenesis: A Control Point for Normal and Delayed Wound Healing, In Li, W.W., Li, V.W.,: Angiogenesis in Wound Healing, Dowden Health Media, Cambridge: 5,7-9.(3)

Meitha dan Windurini. 2003. Pengaruh Daun Lidah Buaya Terhadap Peradangan Jaringan Mukosa Rongga Mulut. JKG UI. 10 (edisi khusus): 472-7.

Mosallam, R.S., Nemat, A., El-Hoshy, A., and Suzuki, S., 2011, Effect of Oleozon on Healing of Exposed Pulp Tissues, Journal of American Science, 7(5):38-44.

Nancy, A. 2003. Ten Cate's Oral Histology: development, structure, and function. $6^{\text {th }} \mathrm{ed}$. St.Louis: Mosby. 115-119.

Nogales, C.G., Ferrari, P.A., and Kantorovich, E.O. 2008. Ozone Therapy in Medicine and Dentistry.J Contemp Dent Pract. 9(4):75-84.

Nursal, F.K., Indriani, O., dan Dewantini, L.A., 2010, Penggunaan Na-CMC Sebagai Gelling Agent Dalam Formula Pasta Gigi Ekstrak Etanol 70\% Daun Jambu Biji (Psidium guajava L), Farmasains, 1(1): 45-51.

Ozdemir, H., Toker, H., Balc, H., and Ozer, H., 2013, Effect of ozone therapy on autogenous bone graft healing in calvarial defects: a histologic and histometric study in rats, J Periodont Res., Vol 48: 722-726.

Roberts, H.C., Moseley, R., Sloan, A.J., Youde, and Waddington, R.J. 2008. Lypopolysaccharida Alters Decorin and Biglycan Synthesis in Rat Alveolar Bone Osteoblasts: Consequences 
for Bone Repair During Periodontal Disease. J. Oral Science. 116; 207-216.

Rowe, R,C., Sheskey P.J. dan Owen, S.C., 2006, Handbook of Pharmaceutical Excipients, Pharmaceut Press, London: 918.

Sintessa, S., Soemarko, H.M., Suprapti, L., dan Hernawan, I. 2013. Hambatan Prostaglandin pada Pemberian OAINS dan Non-OAINS Pasca Pemakaian Alat Ortodontik. J.Exp. Life Sci. 3(2): 65-75.
Srinivasan, K., Chitra, S., 2015, The Application of Ozone in Dentistry: A Systematic Review of Literature, Sch. J. Dent. Sci, 2(6):373-377.

Uchida, S., Sakai, A., Kudo, H., Otomo, H., Watanuki, M., Tanaka, M., Nagashima, M., and Nakamura, T., 2003, Vascular Endothelial Growth Factor is Expressed Along with Its Receptors during The Healing Process of Bone and Bone Marrow After Drill-Hole Injury in Rats, Bone, vol.32 issue 5: 491-501. 